\title{
A Molecular Beacon Lighting up on Graphene Oxide
}

\author{
Po-Jung Jimmy Huang and Juewen Liu* \\ Department of Chemistry, Waterloo Institute for Nanotechnology, University of Waterloo, Waterloo, \\ Ontario, N2L 3G1, Canada
}

Email: liujw@uwaterloo.ca

\begin{abstract}
A molecular beacon (MB) is comprised of a fluorophore and a quencher linked by a DNA hairpin. MBs have been widely used for homogeneous DNA detection. In addition to molecular quenchers, many nanomaterials such as graphene oxide (GO) also possess excellent quenching efficiency. Most reported fluorescent sensors relied on DNA probes physisorbed by GO, which may suffer from non-specific probe displacement and false positive signal. In this work, we report the preparation and characterization of a MB using graphene oxide (GO) as quencher, where an amino and FAM (6carboxyfluorescein) dual labeled DNA was covalently attached to GO via an amide linkage. A major challenge was to remove noncovalently attached probes due to strong DNA adsorption by GO. While DNA desorption was favored at low salt, high $\mathrm{pH}$, high temperature, and by using organic solvents, the complementary DNA was required to achieve complete desorption of non-covalently linked DNA probes. The DNA adsorption energy was measured using isothermal titration calorimetry, revealing the heterogeneous nature of GO. The covalent probe has a detection limit of $2.2 \mathrm{nM}$ using a sample volume of $0.05 \mathrm{~mL}$. With $2 \mathrm{~mL}$ sample, the detection limit can reach $150 \mathrm{pM}$. The covalent probe is highly resistant to non-specific probe displacement and will find applications in serum and cellular samples where high probe stability is demanded.
\end{abstract}

This document is the Accepted Manuscript version of a Published Work that appeared in final form in Analytical Chemistry copyright $\odot$ American Chemical Society after peer review and technical editing by publisher. To access the final edited and published work see Huang, P.-J. J., \& Liu, J. (2012). Molecular Beacon Lighting up on Graphene Oxide. Analytical Chemistry, 84(9), 4192-4198. https://doi.org/10.1021/ac300778s 


\section{Introduction}

A molecular beacon (MB) contains a DNA hairpin that positions a fluorophore labeled end of the DNA in the proximity of a quencher labeled on the other end, giving low background fluorescence. A target DNA opens up the hairpin and produces fluorescence. Since its first report in $1996,{ }^{1}$ many improvements have been made on the MB design to increase signal-to-background ratio and specificity. ${ }^{2}$ For example, quantum dots, conjugated polymers and metal nanoclusters have been tested as brighter and more stable fluorophores. ${ }^{3-5}$ The DNA backbone has also been replaced by phosphorothioate DNA, ${ }^{6}$ locked nucleic acids, ${ }^{7}$ and peptide nucleic acids ${ }^{8}$ so that specificity and stability can be further improved. For the quencher role, superquenchers and metal nanoparticles have been tested. ${ }^{9-11}$

In addition to improving photophysical properties, using nanomaterials as MB components offers several other advantages. First, such MBs might be easily separated, allowing for operations unique to heterogeneous assays such as washing and signal amplification. In addition, nanomaterials may protect DNA and facilitate DNA delivery into cells, ${ }^{12-14}$ avoiding the use of transfection agents or microinjection. ${ }^{15-17}$ Finally, several different probes can be attached to the same particle for multiplexed detection. ${ }^{18,19}$ Recently, a number of fluorescent sensors have been prepared using carbon-based nanomaterials as quenchers (e.g. carbon nanotubes and graphene oxide). ${ }^{20-26}$ Graphene is a single layer of graphite with many superior electronic and mechanical properties. ${ }^{27-30}$ By generating surface hydroxyl and carboxyl groups, the resulting graphene oxide (GO) can disperse in water. GO strongly adsorbs nonstructured single-stranded (ss-DNA), while adsorption of well-folded or double-stranded (ds) DNA is disfavored. Combined with its superior fluorescence quenching ability, a number of sensors have been prepared to detect metal ions, ${ }^{31,32}$ small molecules, ${ }^{13,33,34}$ proteins, ${ }^{35}$ DNA,${ }^{36-41}$ and cells. ${ }^{42}$ Most of these sensors were designed using a scheme shown in Figure 1A. For example, a fluorescent probe DNA is adsorbed by GO. Addition of its complementary DNA (cDNA) induces probe desorption and 
fluorescence enhancement. While effective sensing has been achieved, non-specific probe displacement might occur to produce a false positive signal. These sensors are called non-covalent sensors in this paper since the probe DNA is only physisorbed by GO. For the same reason, these sensors are not MBs. With the probe DNA leaving GO surface upon target binding, continuous monitoring is difficult (e.g. under a flow condition). A natural solution to tackle these problems is to covalently link the probe DNA to GO. ${ }^{43-}$
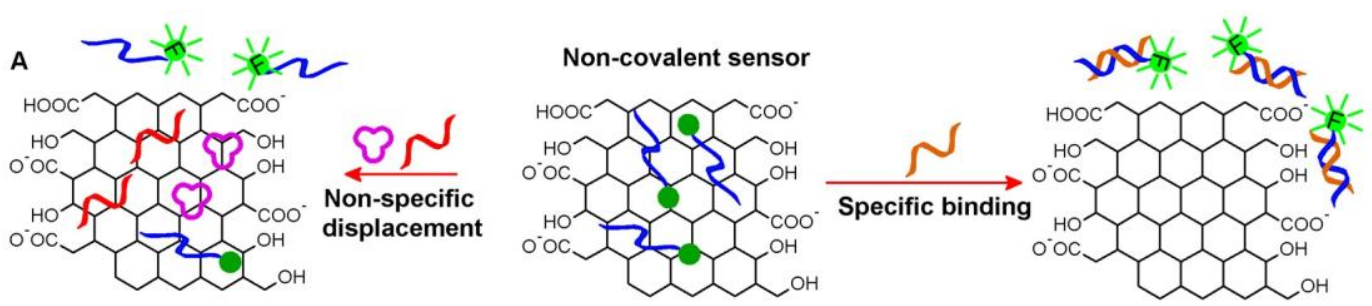

B

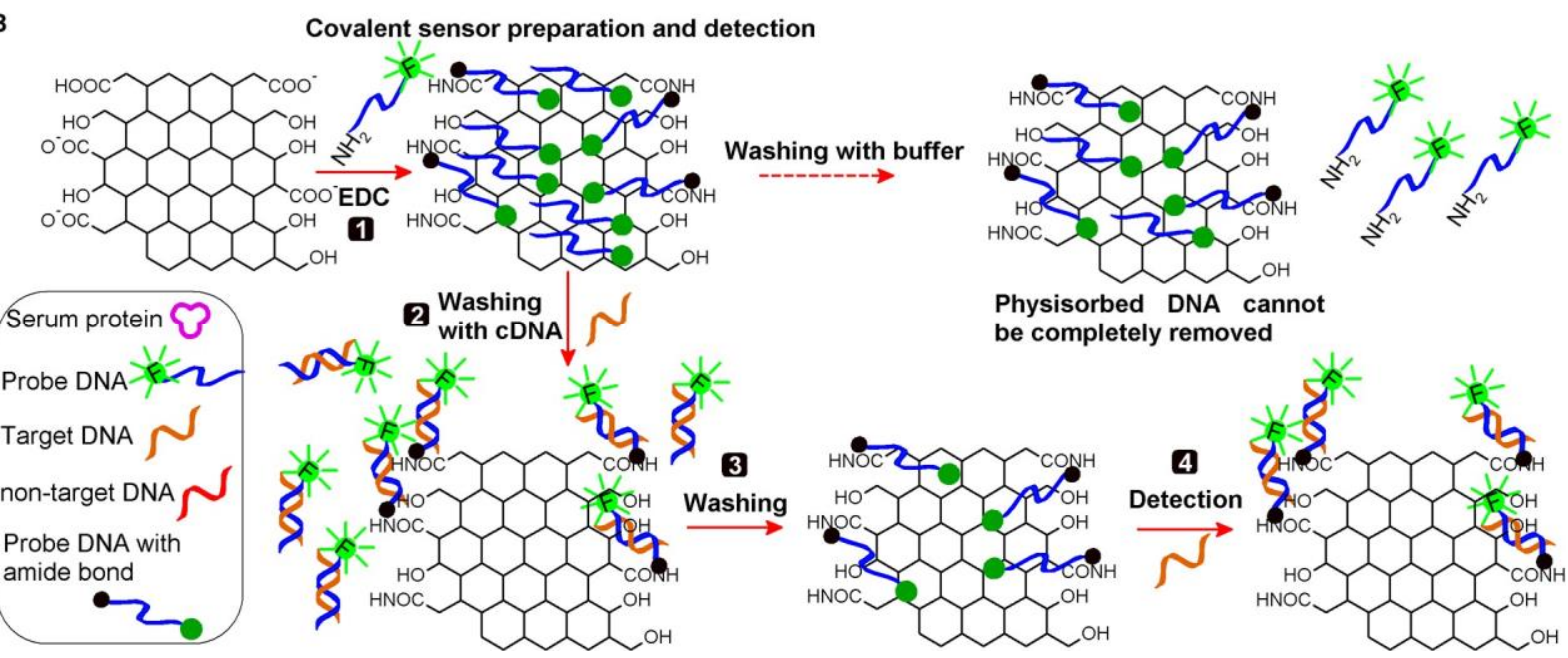

Figure 1. (A) Schematic presentation of non-covalent sensor that might generate a false signal by probe displacement or a true signal by forming duplex DNA. (B) Covalent linking amino-modified DNA to GO can be achieved using EDC coupling (step 1), but only a fraction of the DNA is covalently attached while the remaining ones are physisorbed. Washing in buffer cannot completely remove physisorbed DNA. Complete desorption requires washing with cDNA (step 2). Next the cDNA needs to be washed away (step 3). The covalent sensor can then be used for detection (Step 4). It is likely that some of the cDNA 
also remain on the GO surface after washing. For the clarity of the figure, the aromatic structure in GO is not drawn.

Mohanty and Berry covalently linked a non-fluorescent DNA to GO, and they observed fluorescence signal on the GO surface after hybridization with a fluorescent cDNA. ${ }^{43}$ For practical analytical applications, the use of non-labeled target DNA is more desirable. We recently attached a set of amino and FAM (6-carboxyfluorescein) dual labeled DNAs to GO using EDC (1-ethyl-3(3dimethyllaminopropyl)carbodiimide hydrochloride) as the coupling agent and measured distancedependent fluorescence energy transfer to GO after adding an excess amount of cDNA. ${ }^{45}$ This work has established the useful distance range for fluorescence signaling on GO and suggested the feasibility of designing covalent fluorescent probes. However, important analytical questions such as sensitivity, specificity, non-specific probe displacement, and sensor regeneration have not been tested. Since GO strongly adsorbs ss-DNA and the EDC coupling efficiency is unlikely to be $100 \%$, there are physisorbed DNA probes in addition to covalently linked ones. To prepare real MBs, the physisorbed probes need to be removed, which turned out to be quite difficult. In this work, we report the preparation and characterization of a MB using GO as a quencher. The washing conditions have been carefully optimized and related DNA adsorption energy and adsorption activation energy have been measured.

\section{Experimental Section}

Covalent attaching DNA to GO. The conjugation reaction was carried out for $3 \mathrm{~h}$ at room temperature under magnetic stirring in a glass vial with a final volume of $500 \mu \mathrm{L}$ containing $100 \mu \mathrm{g} / \mathrm{mL} \mathrm{GO}, 2 \mu \mathrm{M}$ amino-modified probe DNA, $10 \mathrm{mM}$ EDCDHCl (freshly prepared), $25 \mathrm{mM} \mathrm{NaCl}$ and $25 \mathrm{mM} \mathrm{MES}(\mathrm{pH}$ 6.0). The GO/DNA complex was purified by centrifugation at $15000 \mathrm{rpm}$ for $20 \mathrm{~min}$ followed by removing the supernatant and washing with $500 \mu \mathrm{L}$ of water twice to further remove non-associated DNA. 
To remove non-covalently attached DNA, the sample was washed with $80 \%$ isopropanol followed by dispersing the sample in $5 \mathrm{mM}$ pH 9.5 Tris. Sonication was performed occasionally to assist dispersing. This procedure was repeated two more times. The sample was then dispersed in buffer

A (25 mM HEPES, pH 7.6, $150 \mathrm{mM} \mathrm{NaCl}, 1 \mathrm{mM} \mathrm{MgCl}_{2}$ ) containing $4 \mu \mathrm{M}$ cDNA to fully desorb physisorbed DNA probes. Finally, cDNA was washed away using $80 \%$ isopropanol followed by $5 \mathrm{mM}$ Tris, pH 9.5 at $75^{\circ} \mathrm{C}$. The covalent sensor was dispersed in buffer $\mathrm{A}$ and stored at $4{ }^{\circ} \mathrm{C}$ with a final GO concentration of $100 \mu \mathrm{g} / \mathrm{mL}$.

DNA detection. To test sensor performance, the fluorescence was measured using a microplate reader

(Tecan Infinite F200 Pro). In each well, $50 \mu \mathrm{L}$ of the covalently linked sensor was dispersed in buffer A ( $\mathrm{GO}$ concentration $=20 \mu \mathrm{g} / \mathrm{mL}$ ). After monitoring the background fluorescence for $\sim 15 \mathrm{~min}$, small volumes (usually <5 पL) of target DNA was added to achieve designated final cDNA concentrations and the fluorescence was monitored for at least $45 \mathrm{~min}$. Similar procedures were used for measuring selectivity with a DNA containing a single base mismatch. Additional experimental procedures are in Supporting Information.

\section{Results and Discussion}

Covalent sensor preparation. We reacted a 24-mer probe DNA containing a 5'-FAM and a 3'-amino with carboxyl GO using EDC as the coupling reagent to form an amide bond (Figure 1B, step 1). After washing away the non-associated DNA with water and centrifugation, the purified GO/DNA complex was re-dispersed in buffer A (25 mM HEPES, pH 7.6, $150 \mathrm{mM} \mathrm{NaCl}, 1 \mathrm{mM} \mathrm{MgCl} 2$ ). Addition of the cDNA resulted in >100-fold fluorescence increase (Figure S1, Supporting Information). Following the cDNA reaction, this sample was centrifuged. Its supernatant fluorescence (i.e. free DNA) intensity was 300 units, while fluorescence from the re-dispersed GO pellet (i.e. covalently attached probes) was only $\sim 70$, 
suggesting the presence of a large fraction of non-covalently attached probes. The EDC coupling efficiency was estimated to be only $\sim 17 \%$ (see Supporting Information). We next measured the fluorescence anisotropy of the GO pellet to be $\sim 0.11$ and the supernatant to be $\sim 0.08$, further confirming that the supernatant contained the free DNA with a lower anisotropy. Therefore, to prepare real MBs, the $\sim 83 \%$ physisorbed DNA without a covalent linkage needs to be removed.
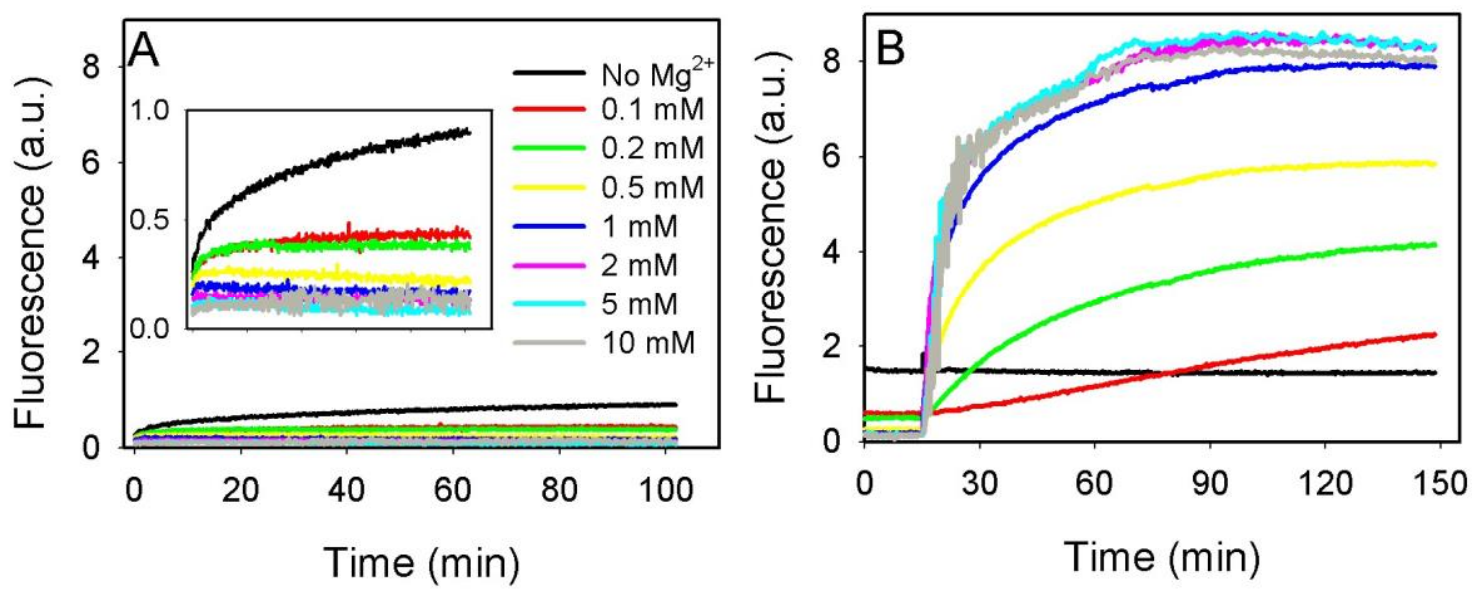

Figure 2. Kinetics of DNA desorption in the presence of various $\mathrm{Mg}^{2+}$ concentrations at room temperature in the absence (A) or presence (B) of $4 \mu \mathrm{M}$ cDNA. The legend indicates $\mathrm{Mg}^{2+}$ concentration. Inset of (A): the same plot at a smaller $y$-axis scale.

DNA desorption by reducing ionic strength. Since DNA desorption from GO is a crucial step for many biosensors, we systematically studied this process. This information is also useful for other carbon-based materials that interact with DNA via similar mechanisms. First, the FAM-labeled probe DNA was physisorbed onto GO (no EDC reaction), and DNA desorption was monitored by fluorescence enhancement. Since both DNA and GO are negatively charged, reducing ionic strength should increase electrostatic repulsion and facilitate desorption. To test this, the GO/DNA complex was dispersed in buffers with various concentrations of $\mathrm{MgCl}_{2}$. The kinetics of fluorescence change is presented in Figure 
2A, where the $y$ axis covers the range of expected fluorescence for complete desorption. Desorption was quite low for all the samples. The inset is the same figure at a smaller scale.

While desorption was faster with a lower salt concentration, even in the absence of salt, desorption after 100 min only reached $\sim 15 \%$, which barely charged after overnight incubation (data not shown). This study confirms that although DNA was more easily desorbed in a low salt buffer, washing in water still leaves $>80 \%$ of physisorbed DNA. These samples were then exposed to $4 \mu \mathrm{M}$ cDNA to induce probe desorption (Figure 2B). Except for the sample dispersed in water, all showed fluorescence increase, confirming the presence of a large amount of probe DNA on GO.
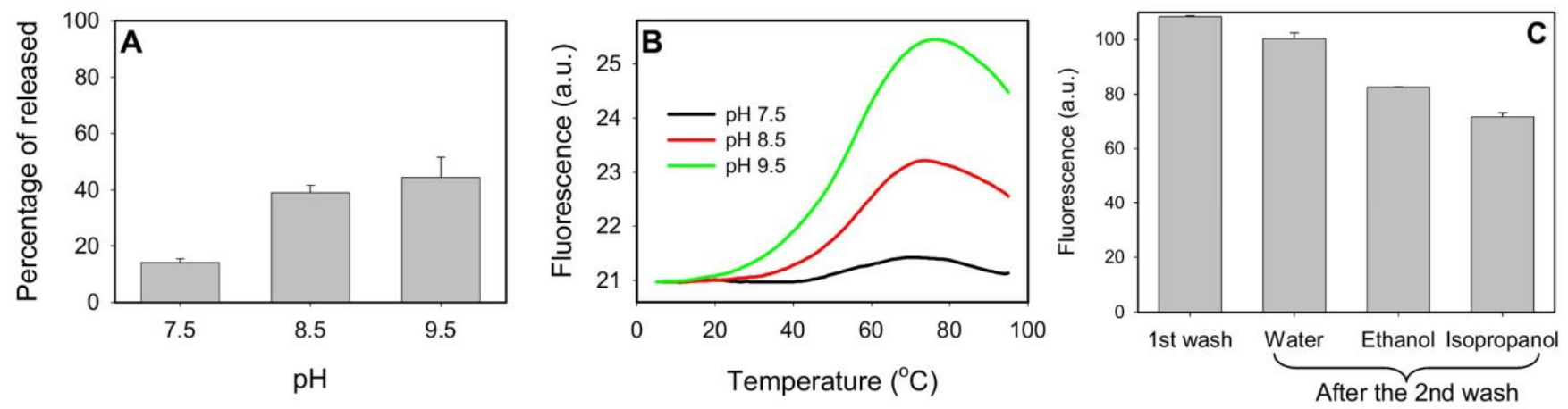

Figure 3. (A) Percentage of DNA desorption after incubation in low salt buffers at different $\mathrm{pH}$ values for $3 \mathrm{hrs}$. The final fluorescence measurement was carried out at the same $\mathrm{pH}$ to avoid artifacts associated with pH-dependent FAM quantum yield variation. (B) Thermal desorption of DNA (5 mM Tris- $\mathrm{HCl}$ buffers without additional salt). The background fluorescence of the instrument was at $\sim 20$ fluorescence unit. (C) After washing with $5 \mathrm{mM}$ Tris buffer at $\mathrm{pH} 9.5$ and $75^{\circ} \mathrm{C}$, the sample was divided into four tubes. One was not further washed (first bar). The other three were respectively washed in water, $80 \%$ ethanol or isopropanol. The fluorescence after adding $4 \mu \mathrm{M}$ cDNA was plotted. 
Desorption at high pH. The electrostatic repulsion between DNA and GO can also be increased by raising $\mathrm{pH}^{46,47}$ We tested three buffers (5 mM each) at $\mathrm{pH} 7.5,8.5$, and 9.5 without additional salt. After centrifugation the supernatant fluorescence containing desorbed DNA was measured (Figure 3A). The highest desorption was achieved at $\mathrm{pH} 9.5$, approaching 50\%. Desorption at $\mathrm{pH} 7.5$ was the lowest, comparable to the $\sim 15 \%$ obtained from Figure $2 \mathrm{~A}$. Further increase of $\mathrm{pH}$ was not tested to avoid the reduction of GO, since reduced GO binds DNA more tightly and is easily aggregated. ${ }^{48}$

Thermal desorption. To further assist desorption, we next increased temperature. Three GO/DNA samples were loaded into a real-time PCR thermocycler and their fluorescence was monitored as a function of temperature (Figure 3B). Higher fluorescence was observed at higher temperature, suggesting more effective DNA desorption. Therefore, a combination of high $\mathrm{pH}$, low salt and high temperature was tested to achieve effective DNA desorption. By incubating $20 \mu \mathrm{g} / \mathrm{mL} \mathrm{GO}$ with $200 \mathrm{nM}$ adsorbed DNA in $5 \mathrm{mM}$ Tris, $\mathrm{pH} 9.5$ at $75^{\circ} \mathrm{C}$ for $10 \mathrm{~min}$, we were able to remove $\sim 77 \%$ of the adsorbed DNA. This washing protocol was repeated under the identical conditions, but only $\sim 3 \%$ was removed for the second wash (Figure S2), still leaving 20\% physisorbed DNA on GO.

Desorption using organic solvents. The above studies indicate that $\sim 40 \mathrm{nM}$ DNA $(\mathrm{GO}=20 \mu \mathrm{g} / \mathrm{mL})$ cannot be washed away in aqueous buffers under all the tested conditions. Hydrophobic and base stacking interactions are the main attractive forces for DNA adsorption by GO, ${ }^{49-51}$ which might be weakened by using organic solvents. To better observe the solvent effect, a two-step washing procedure was performed. The sample was first washed with $5 \mathrm{mM}$ Tris $(\mathrm{pH} 9.5)$ at $75^{\circ} \mathrm{C}$ to remove $\sim 80 \%$ of DNA followed by a second wash in water, $80 \%$ ethanol or $80 \%$ isopropanol. The remaining DNA was measured after incubating with $4 \mu \mathrm{M}$ cDNA. As shown in Figure 3C, while isopropanol was the most effective for further DNA desorption, $~ 15 \%$ of DNA was still adsorbed. Similar results were obtained by direct washing using isopropanol without performing the pre-washing step (Figure S3). These washing experiments suggest 
that the GO surface is very heterogeneous and some regions adsorb DNA with an extremely high affinity. DNAs adsorbed on the low affinity regions are more easily desorbed.

Adsorption energy and desorption activation energy. To quantitatively understand the extremely high binding affinity between DNA and GO, the heat of DNA adsorption was measured using isothermal titration calorimetry (ITC). The same 24-mer DNA sequence but without any modification was gradually injected into a GO sample and released heat was measured. For the first three injections, close to complete adsorption was achieved (Figure S4). Therefore, DNA adsorption energy can be directly calculated. The released heat progressively decreased as more DNA was injected (Figure 4A), confirming the presence binding sites with different binding energies. It is known that the GO surface is highly heterogeneous from microscopy and spectroscopic studies, ${ }^{52-55}$ containing both carbon rich pristine graphene regions and highly oxidized regions. DNA adsorption on the carbon rich regions should be more favorable and thus release more heat. Our ITC result is also consistent with the thermal desorption experiment (Figure 3B), where DNA desorption occurred over a wide temperature range without a sharp transition, indicating different binding affinities.
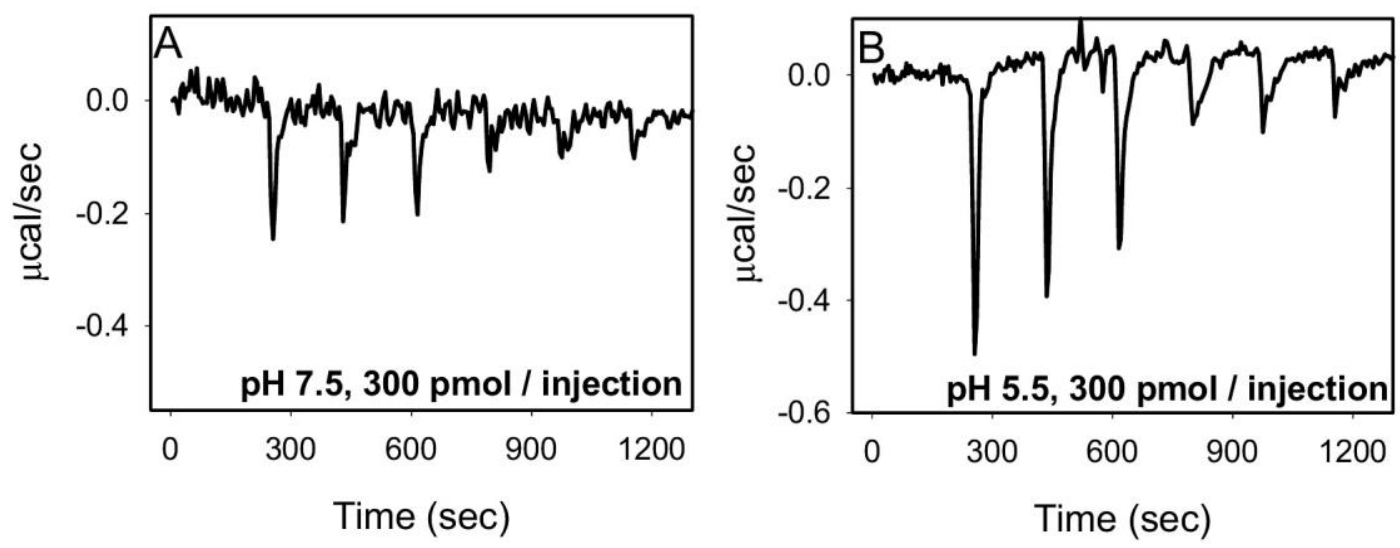

Figure 4. Measuring the heat of DNA adsorption onto GO using ITC. The experiments were performed at $\mathrm{pH} 7.5$ (A) and 5.5 (B). Both GO and DNA were dispersed in $150 \mathrm{mM} \mathrm{NaCl}, 1 \mathrm{mM} \mathrm{MgCl} 2$ with 25 $\mathrm{mM}$ buffer (HEPES for $\mathrm{pH} 7.5$ or citrate for $\mathrm{pH} 5.5$ ). 
We estimated the highest adsorption energy at $\mathrm{pH} 7.5$ to be $\Delta H_{a d s}=61.3 \mathrm{~kJ} / \mathrm{mol}$ by measuring the heat from the first injection. The heat progressively decreased with the second injection being 47.9 and the third being $32.7 \mathrm{~kJ} / \mathrm{mol}$. Since lowering $\mathrm{pH}$ facilitates DNA binding, we further measured the heat at pH 5.5 to be $89.0,92.8$, and $80.3 \mathrm{~kJ} / \mathrm{mol}$ for the first three injections (Figure 4B). For adsorption energy greater than $100 \mathrm{~kJ} / \mathrm{mol}$, it can be considered chemisorption or covalent bonding. Such high adsorption energy explains the difficulties associated with complete DNA desorption. This adsorption energy contributes to only part of desorption activation energy, which should be the sum of adsorption energy and adsorption activation energy. We measured the adsorption activation energy to be $31.6 \mathrm{~kJ} / \mathrm{mol}$ in a low salt buffer, further contributing the difficulties associated with complete desorption (Figures S5-S7).

Desorption with cDNA. While our above rinsing efforts failed to completely remove physisorbed DNA, they provided important insights into the interaction between DNA and GO. Since cDNA forms a stable duplex with the probe DNA, we added cDNA in the washing buffer to achieve complete desorption (Figure 1B, step 2). The next step was to remove the cDNA under our best washing conditions. Although it is unlikely that cDNA could be completely removed, we reason that as long as the residual cDNA does not interfere with detection, its effect could be neglected. The resulting sample was dark under blue light excitation (Figure 5A), indicating that all the DNAs were associated with GO. Addition of the cDNA produced a highly fluorescent sample. After overnight incubation, most of the GO sheets settled down and the fluorescence was associated with GO. After centrifugation, the whole solution turned dark and only the pellet was slightly fluorescent since GO absorbed most of the light in the pellet. This experiment indicated that all the fluorophores were covalently attached to GO and a covalent sensor was successfully prepared. For comparison, adding the cDNA to the non-covalent sensor resulted in high fluorescence that remained in the supernatant after centrifugation (Figure 5B). 
Displacement assays. One of the main motivations for developing the covalent sensor is to reduce nonspecific probe displacement. To test this, the covalent sensor was incubated with $500 \mathrm{nM}$ cDNA as well as the probe DNA sequence but without the FAM label. As shown in Figure 5C, fluorescence increased significantly with the cDNA but barely changed with the same DNA. For the non-covalent sensor, on the other hand, a significant signal increase was observed with even the same DNA (Figure 5D), indicating non-specific probe displacement. One possible way to reduce probe displacement is to use a lower the probe concentration, so that more free surface area is still available on GO to accommodate competing DNAs. To test this, the concentration of the probe DNA was reduced from 500 to $50 \mathrm{nM}$ with the same GO concentration (inset of Figure 5D). While the absolute value of the displacement signal decreased, the signal caused by the cDNA also decreased to a similar extent (note the scale on the $y$-axis). Therefore, in the non-covalent case, it is difficult to avoid non-specific probe displacement.
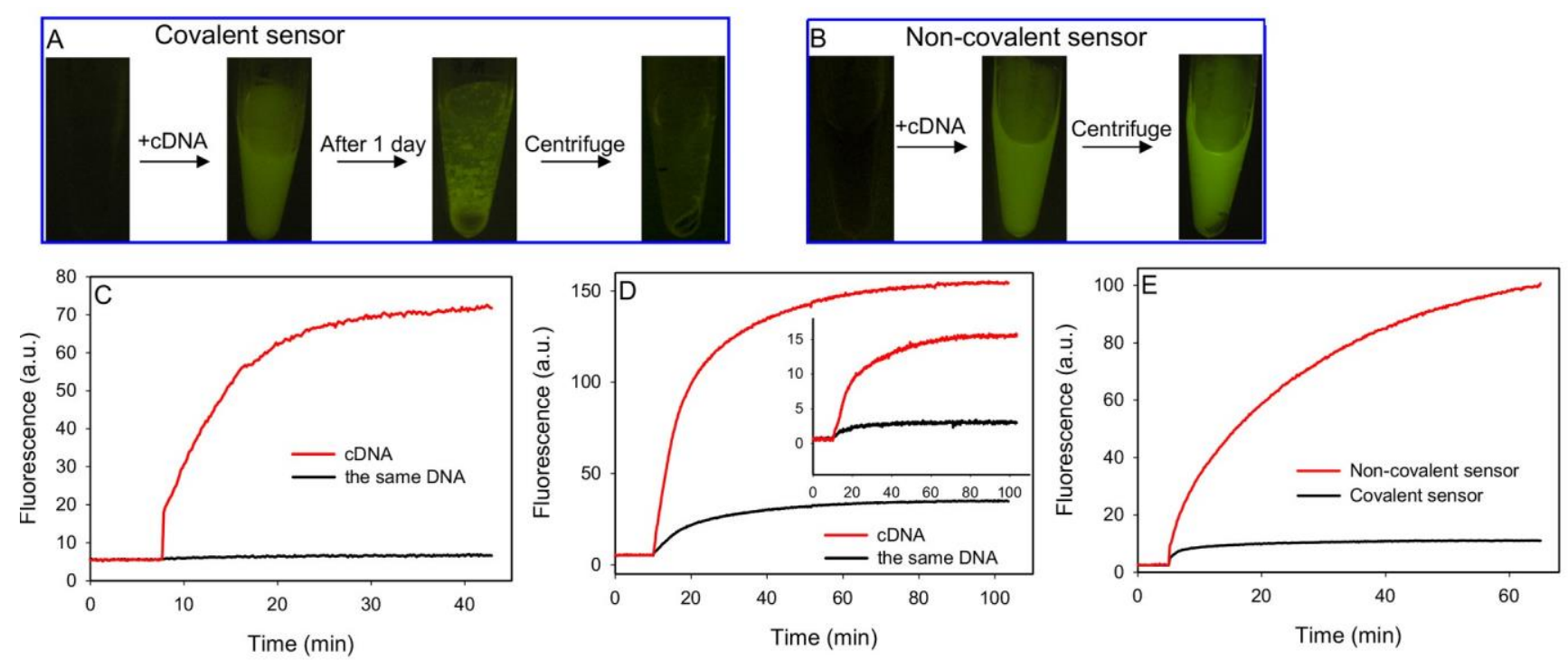

Figure 5. Fluorescence photographs of covalent (A) and non-covalent (B) sensors after reacting with the cDNA and centrifugation. Response of the covalent sensor (C) and non-covalent sensor with $500 \mathrm{nM}$ adsorbed probe DNA (D) or $50 \mathrm{nM}$ probe DNA (inset of D) in the presence of $500 \mathrm{nM}$ cDNA or the same DNA. (E) Response of the covalent and non-covalent sensors to $0.5 \%$ BSA. 
To mimic the serum sample matrix, the covalent and non-covalent sensors were respectively exposed to $0.5 \%$ bovine serum albumin (BSA). The fluorescence increased significantly and continuously for the non-covalent sensor, but the increase for the covalent sensor was very moderate and stopped after the first a few minutes. These displacement assays highlighted one of the main advantages of the covalent sensor for improving sensor specificity. This is particularly important for performing detection in serum samples and for intracellular assays, where a high concentration of background nucleic acids and proteins are present.
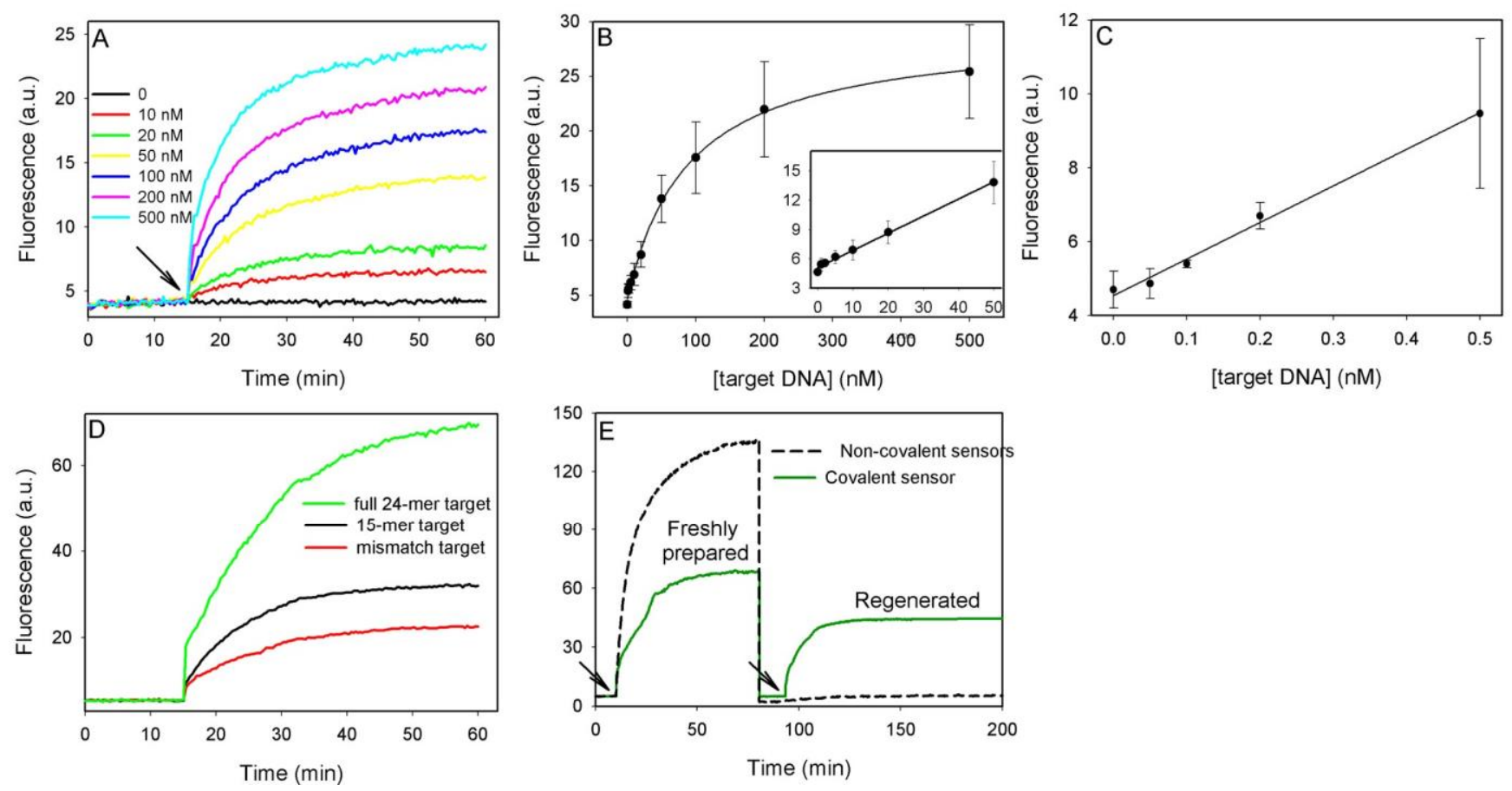

Figure 6. (A) Kinetics of covalent sensor fluorescence increase in the presence of varying concentrations of the 15-mer target DNA. (B) Fluorescence at $20 \mathrm{~min}$ after target addition as a function of target concentration. Inset: response at low target DNA concentrations. (C) Sensor response with a sample volume of $2 \mathrm{~mL}(50 \mu \mathrm{L}$ in (A) and (B)). (D) Kinetics of fluorescence increase with the full 24mer target 
and a 15-mer mismatched target. (E) Senor regeneration; $4 \mu \mathrm{M}$ cDNA was added at the time points indicated by the arrow heads.

Sensitivity and selectivity. After preparing the covalent sensor, we tested its sensitivity using a 15-mer DNA target complementary to the top portion of the 24-mer probe (i.e. the portion close to the FAM label). As shown in Figure 6A, the background signal was very stable. A higher target DNA concentration generated a higher signal, forming the basis for quantitative detection. If the fluorescence increase at 20 min after adding the target DNA is compared (Figure 6B), the detection limit is $2.2 \mathrm{nM}$ based on the signal intensity being three times higher than that of background variation. This detection limit is comparable to that reported for non-covalently sensors (e.g. $\sim 1 \mathrm{nM}) .{ }^{38}$ Therefore, the covalent attachment of the probe to GO did not significantly compromise sensitivity. In our system, GO is not only a quencher but also a substrate for sensor immobilization, allowing target enrichment. To test this, we incubated the GO probes in $2 \mathrm{~mL}$ of sample (previously $50 \mu \mathrm{L}$ ) followed by centrifugation and redispersing the sample in $50 \mu \mathrm{L}$. Indeed the detection limit was improved to $0.15 \mathrm{nM}$ (Figure 6C). This detection limit is also similar to many other optical sensors for DNA detection without signal amplification (i.e. high pM to low nM). ${ }^{1,56-}$ 58

For our sensitivity test, the target DNA was complementary only to a portion of the 24-mer probe, leaving 9 unpaired nucleotides. If the full 24-mer was used, higher fluorescence intensity was achieved (Figure 6D). This was attributed to that the longer cDNA was able to position the fluorophore farther away from the GO surface, leading to reduced quenching. ${ }^{45,59}$ Even with the full 24-mer cDNA, the intensity of the covalent sensor was less than half of the non-covalent sensor under otherwise identical conditions, ${ }^{45}$ which contributes to the slightly better detection limit of non-covalent sensors. The fact that both the full 24-mer and the top 15-mer targets can work indicates that a flexible DNA spacer can be added. Using a 
15-mer DNA containing a single GDA mismatch, a reduced fluorescence was observed (Figure 6D, red line) and this single base mismatch selectivity was similar to the non-covalent probes using GO as a quencher. ${ }^{36,38}$ With the covalent modification, it should be possible to achieve sensor regeneration. To test this, we washed away the target DNA and the regenerated sensor was collected after centrifugation. As shown in Figure 6E, functional sensor was achieved in the covalent sample but no signal was observed for the non-covalent one. This regeneration experiment also suggested that using an excess amount of cDNA can completely desorb non-covalent probes, validating the use of cDNA to quantify physisorbed DNA probes.

\section{Conclusions.}

In summary, we have prepared a MB for DNA detection based on covalent conjugation of a fluorescent DNA probe to GO. Although no hairpin structure was engineered in the DNA sequence, the fluorophore is positioned nearby the GO quencher by strong adsorption. Inspired by the pioneering works from Tan and Yang groups of using carbon nanotubes and GO for DNA probe adsorption and fluorescent detection, ${ }^{20,36}$ numerous follow-up researches have been carried out. It is interesting to note though, most work employed only physisorbed DNA probes on these carbon quenchers. From this work, we conclude that one of the major issues is to completely remove non-covalently linked probes ( $>80 \%$ of added DNA in our case), so that the generated signals can be correctly interpreted. We found that DNA was adsorbed on GO with various affinities and the most tightly adsorbed ones ( $15-20 \%$ of the surface capacity) cannot be washed away under all tested buffer conditions. The cDNA had to be added for complete desorption. Such covalent probes will find applications for detection in complex biological sample matrix with minimal non-specific probe displacement. 
ACKNOWLEDGMENT. This work is supported by the University of Waterloo, Canada Foundation for Innovation, Early Researcher Award from Ontario Ministry of Research and Innovation, and the Natural Sciences and Engineering Research Council (NSERC) of Canada.

Supporting Information Available: Additional experimental description, DNA sequences and DNA adsorption/desorption energies, kinetics, and long-term storage. This material is available free of charge via the Internet at http://pubs.acs.org.

\section{REFERENCES}

(1) Tyagi, S.; Kramer, F. R. Nat. Biotechnol. 1996, 14, 303-308.

(2) Wang, K. M.; Tang, Z. W.; Yang, C. Y. J.; Kim, Y. M.; Fang, X. H.; Li, W.; Wu, Y. R.; Medley, C. D.; Cao, Z. H.; Li, J.; Colon, P.; Lin, H.; Tan, W. H. Angew. Chem. Int. Ed. 2009, 48, 856870.

(3) Yang, C. Y. J.; Pinto, M.; Schanze, K.; Tan, W. H. Angew. Chem. Int. Ed. 2005, 44, 2572-2576.

(4) Petty, J. T.; Sengupta, B.; Story, S. P.; Degtyareva, N. N. Anal. Chem. 2011, 83, 5957-5964.

(5) Kim, J. H.; Morikis, D.; Ozkan, M. Sensor. Actuat. B-Chem. 2004, 102, 315-319.

(6) Shah, R.; El-Deiry, W. S. Cancer Biol. Ther. 2004, 3, 871-875.

(7) Wu, Y.; Yang, C. J.; Moroz, L. L.; Tan, W. Anal. Chem. 2008, 80, 3025-3028.

(8) Seitz, O. Angew. Chem., Int. Ed. 2000, 39, 3249-3252.

(9) Yang, C. Y. J.; Lin, H.; Tan, W. H. J. Am. Chem. Soc. 2005, 127, 12772-12773.

(10) Dubertret, B.; Calame, M.; Libchaber, A. J. Nat. Biotechnol. 2001, 19, 365-370.

(11) Maxwell, D. J.; Taylor, J. R.; Nie, S. J. Am. Chem. Soc. 2002, 124, 9606-9612.

(12) Sun, X. M.; Liu, Z.; Welsher, K.; Robinson, J. T.; Goodwin, A.; Zaric, S.; Dai, H. J. Nano Research 2008, 1, 203-212. 
(13) Wang, Y.; Li, Z. H.; Hu, D. H.; Lin, C. T.; Li, J. H.; Lin, Y. H. J. Am. Chem. Soc. 2010, 132, 9274-9276.

(14) Rosi, N. L.; Giljohann, D. A.; Thaxton, C. S.; Lytton-Jean, A. K. R.; Han, M. S.; Mirkin, C. A. Science 2006, 312, 1027-1030.

(15) Bratu, D. P.; Cha, B.-J.; Mhlanga, M. M.; Kramer, F. R.; Tyagi, S. Proc. Natl. Acad. Sci. U.S.A. 2003, 100, 13308-13313.

(16) Medley, C. D.; Drake, T. J.; Tomasini, J. M.; Rogers, R. J.; Tan, W. Anal. Chem. 2005, 77, 4713-4718.

(17) Nitin, N.; Santangelo, P. J.; Kim, G.; Nie, S.; Bao, G. Nucleic Acids Res. 2004, 32, e58.

(18) Song, S. P.; Liang, Z. Q.; Zhang, J.; Wang, L. H.; Li, G. X.; Fan, C. H. Angew. Chem. Int. Ed. 2009, 48, 8670-8674.

(19) Zhang, M.; Yin, B.-C.; Tan, W.; Ye, B.-C. Biosens. Bioelectron. 2011, 26, 3260-3265.

(20) Yang, R. H.; Jin, J. Y.; Chen, Y.; Shao, N.; Kang, H. Z.; Xiao, Z.; Tang, Z. W.; Wu, Y. R.; Zhu, Z.; Tan, W. H. J. Am. Chem. Soc. 2008, 130, 8351-8358.

(21) Yang, R. H.; Tang, Z. W.; Yan, J. L.; Kang, H. Z.; Kim, Y. M.; Zhu, Z.; Tan, W. H. Anal. Chem. 2008, 80, 7408-7413.

(22) Liu, S.; Li, H.; Wang, L.; Tian, J.; Sun, X. J. Mater. Chem. 2011, 21, 339-341.

(23) Li, H.; Zhang, Y.; Luo, Y.; Sun, X. Small 2011, 7, 1562-1568.

(24) Yang, W. R.; Ratinac, K. R.; Ringer, S. P.; Thordarson, P.; Gooding, J. J.; Braet, F. Angew. Chem. Int. Ed. 2010, 49, 2114-2138.

(25) Wang, Y.; Li, Z. H.; Wang, J.; Li, J. H.; Lin, Y. H. Trends Biotechnol. 2011, 29, 205-212.

(26) Wang, H.; Yang, R. H.; Yang, L.; Tan, W. H. ACS Nano 2009, 3, 2451-2460.

(27) Novoselov, K. S.; Geim, A. K.; Morozov, S. V.; Jiang, D.; Zhang, Y.; Dubonos, S. V.; 
Grigorieva, I. V.; Firsov, A. A. Science 2004, 306, 666-669.

(28) Geim, A. K.; Novoselov, K. S. Nat. Mater. 2007, 6, 183-191.

(29) Allen, M. J.; Tung, V. C.; Kaner, R. B. Chem. Rev. 2009, 110, 132-145.

(30) Rao, C. N. R.; Sood, A. K.; Subrahmanyam, K. S.; Govindaraj, A. Angew. Chem. Int. Ed. 2009, $48,7752-7777$.

(31) Wen, Y. Q.; Xing, F. F.; He, S. J.; Song, S. P.; Wang, L. H.; Long, Y. T.; Li, D.; Fan, C. H. Chem. Comm. 2010, 46, 2596-2598.

(32) He, S. J.; Song, B.; Li, D.; Zhu, C. F.; Qi, W. P.; Wen, Y. Q.; Wang, L. H.; Song, S. P.; Fang, H. P.; Fan, C. H. Adv. Funct. Mater. 2010, 20, 453-459.

(33) Song, Y. J.; Qu, K. G.; Zhao, C.; Ren, J. S.; Qu, X. G. Adv. Mater. 2010, 22, 2206-2210.

(34) Lu, C.-H.; Li, J.; Lin, M.-H.; Wang, Y.-W.; Yang, H.-H.; Chen, X.; Chen, G.-N. Angew. Chem., Int. Ed. 2010, 49, 8454-8457.

(35) Chang, H. X.; Tang, L. H.; Wang, Y.; Jiang, J. H.; Li, J. H. Anal. Chem. 2010, 82, 2341-2346. (36) Lu, C. H.; Yang, H. H.; Zhu, C. L.; Chen, X.; Chen, G. N. Angew. Chem. Int. Ed. 2009, 48, 4785-4787.

(37) Dong, H. F.; Gao, W. C.; Yan, F.; Ji, H. X.; Ju, H. X. Anal. Chem. 2010, 82, 5511-5517.

(38) ～Li, F.; Huang, Y.; Yang, Q.; Zhong, Z. T.; Li, D.; Wang, L. H.; Song, S. P.; Fan, C. H. Nanoscale 2010, 2, 1021-1026.

(39) Zhou, M.; Zhai, Y. M.; Dong, S. J. Anal. Chem. 2009, 81, 5603-5613.

(40) Guo, Y.; Deng, L.; Li, J.; Guo, S.; Wang, E.; Dong, S. ACS Nano 2011, 5, 1282-1290.

(41) Wu, W.; Hu, H.; Li, F.; Wang, L.; Gao, J.; Lu, J.; Fan, C. Chem. Comm. 2011, 47, 1201-1203.

(42) Wang, L.; Pu, K.-Y.; Li, J.; Qi, X.; Li, H.; Zhang, H.; Fan, C.; Liu, B. Adv. Mater. 2011, 23, 4386-4391. 
(43) Mohanty, N.; Berry, V. Nano Lett. 2008, 8, 4469-4476.

(44) Dubuisson, E.; Yang, Z. Y.; Loh, K. P. Anal. Chem. 2011, 83, 2452-2460.

(45) Huang, P.-J. J.; Liu, J. Small 2012, 8, 977-983.

(46) Wu, M.; Kempaiah, R.; Huang, P.-J. J.; Maheshwari, V.; Liu, J. Langmuir 2011, 27, 2731-2738.

(47) Huang, P.-J. J.; Kempaiah, R.; Liu, J. J. Mater. Chem. 2011, 21, 8991-8993.

(48) Liu, J.; Li, Y.; Li, Y.; Li, J.; Deng, Z. J. Mater. Chem. 2010, 20, 900-906.

(49) Ortmann, F.; Schmidt, W. G.; Bechstedt, F. Phys. Rev. Lett. 2005, 95, 186101.

(50) Gowtham, S.; Scheicher, R. H.; Ahuja, R.; Pandey, R.; Karna, S. P. Phys. Rev. B 2007, 76, 033401.

(51) Antony, J.; Grimme, S. Phys. Chem. Chem. Phys. 2008, 10, 2722-2729.

(52) Gomez-Navarro, C.; Meyer, J. C.; Sundaram, R. S.; Chuvilin, A.; Kurasch, S.; Burghard, M.;

Kern, K.; Kaiser, U. Nano Lett. 2010, 10, 1144-1148.

(53) Cai, W.; Piner, R. D.; Stadermann, F. J.; Park, S.; Shaibat, M. A.; Ishii, Y.; Yang, D.;

Velamakanni, A.; An, S. J.; Stoller, M.; An, J.; Chen, D.; Ruoff, R. S. Science 2008, 321, 18151817.

(54) Lerf, A.; He, H.; Forster, M.; Klinowski, J. J. Phys. Chem. B 1998, 102, 4477-4482.

(55) Mkhoyan, K. A.; Contryman, A. W.; Silcox, J.; Stewart, D. A.; Eda, G.; Mattevi, C.; Miller, S.; Chhowalla, M. Nano Lett. 2009, 9, 1058-1063.

(56) Elghanian, R.; Storhoff, J. J.; Mucic, R. C.; Letsinger, R. L.; Mirkin, C. A. Science 1997, 277, 1078-1080.

(57) Xu, K.; Huang, J.; Ye, Z.; Ying, Y.; Li, Y. Sensors 2009, 9, 5534-5557.

(58) Teles, F. R. R.; Fonseca, L. R. Talanta 2008, 77, 606-623.

(59) Piao, Y.; Liu, F.; Seo, T. S. Chem. Comm. 2011, 47, 12149-12151. 